\section{Schlucken statt cremen: Karotinoide schützen vor UV-Strahlung}

\section{Karotinoide, wie sie in Tomaten und Grünkohl enthalten sind, schützen die Haut laut Ergebnissen einer Studie womöglich vor Schäden durch Sonnenlicht.}

E orscher aus Düsseldorf haben die Ergebnisse einer placebokontrollierten, randomisierten Cross-over-Studie zum Sonnenschutz durch orale Karotinoide vorgestellt. Beteiligt waren 65 Probanden, die auf zwei Behandlungsgruppen verteilt wurden. Jede von ihnen bestand aus einer Verum- und einer Placebogruppe, wobei die Zugehörigkeit der Teilnehmer nach einer Auswasch- und einer ersten zwölfwöchigen Behandlungsphase wechselte. Erneutem Auswaschen schloss sich im Cross-over eine erneute zwölfwöchige Therapiephase an.

Als Verum getestet wurde zum einen ein lykopinreicher Nährstoffkomplex aus Tomaten in Kapselform. Die Kapseln enthielten $5 \mathrm{mg}$ Lykopin, dazu weitere Phytonährstoffe wie Phytoen, Phytofluen, Tokopherole und Phytosterole. Die Dosis betrug zweimal täglich zwei Kapseln. Beim zweiten Verum handelte es sich um Kapseln mit 10 mg Lutein, von denen zweimal täglich eine einzunehmen war. In den verwendeten Placebokapseln befand sich Sojaöl.

Jeweils zu Beginn und am Ende einer Therapiephase wurde die Haut der Probanden im Gesäßbereich mit UV-A-/UVB- und UV-A1-Licht bestrahlt. 24 Stunden später entnahmen die Wissenschaftler Hautproben aus unbestrahlter und bestrahlter Haut und untersuchten sie auf Genveränderungen, die für solarstrahlungsbedingte Hautschäden typisch sind.

In der Analyse zeigte sich, dass der Tomaten-Nährstoff-Komplex die UVA-/UV-B- und UV-A1-bedingte Hochregulation von mRNA der Hämoxygenase 1, des interzellulären Adhäsionsmoleküls 1 und der Matrix-Metallopeptidase 1 signifikant hemmt. Auch Lutein bot diesbezüglich einen bedeutsamen Schutz, aber nur, wenn es in der ersten
Therapiephase gegeben wurde. In der zweiten Phase fiel der Effekt verglichen mit dem Tomaten-Nährstoff-Komplex signifikant geringer aus. Die Autoren vermuten, dass die Zeit nicht ausgereicht hatte, um vergleichbare Wirkspiegel wie in der ersten Phase zu erreichen, und das Lutein sich andernorts angereichert hat.

Fazit: Unter der Annahme, dass die genannten Gene Indikatoren für oxidativen Stress, Photodermatosen und lichtbedingte Hautalterung sind, könnten die Resultate Hinweise darauf geben, dass der Tomaten-Nährstoff-Komplex und Lutein vor Hautschäden durch Sonneneinstrahlung schützen, so die Forscher. Kapseln zu schlucken sei dafür ihren Angaben nach nicht nötig. Denn Tagesdosen von $20 \mathrm{mg}$ Lutein und $20 \mathrm{mg}$ Lykopin nimmt bereits zu sich, wer $130 \mathrm{~g}$ zerkleinerten Grünkohl und 242 g Tomatensaft konsumiert. Dr. Robert Bublak

Grether-Beck S et al. Molecular evidence that oral supplementation with lycopene or lutein protects human skin against ultraviolet radiation: results from a double-blinded placebo-controlled, crossover study. $\mathrm{Br} \mathrm{J}$ Dermatol 2017; 176: 1231-40

\section{Eine Riesennase mit krustigen Zacken}

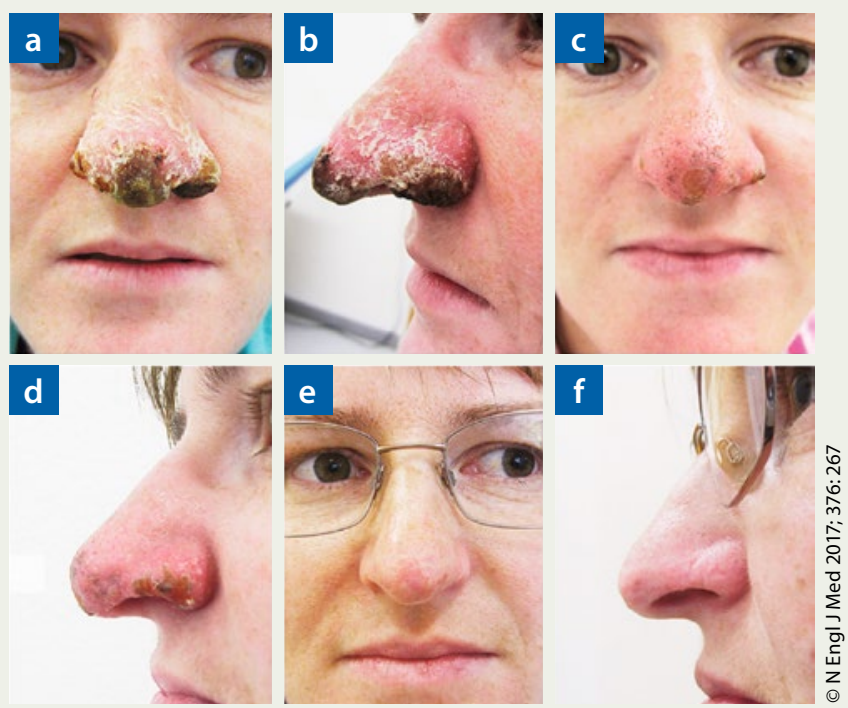

a, b: Geschwollene, ulzerierte Nase; c, d: Erfolg der ersten Antibiotikatherapie; e, f: vollständige Abheilung nach der zweiten Antibiotikatherapie
Eine 37-jährige Frau stellte sich wegen einer seit sechs Wochen bestehenden Schwellung der Nase mit Ulzerationen vor (Abb. a, b). In einer Hautbiopsie aus dem Ulkus konnte Serratia liquefaciens kultiviert werden. Eine dreiwöchige Behandlung mit Ciprofloxacin führte zu einer gewissen Besserung (Abb. C, d). Fünf Wochen später war in der Kultur der Biopsien Mycobacterium marinum gewachsen, der Erreger des Aquarium-Granuloms. In den Biopsien hatte man auch verkäsende Granulome gefunden. Man behandelte sieben Monate lang mit Clarithromycin und Ethambutol. Sechs Monate danach waren die Läsionen abgeheilt (Abb. e, f).

Beide hier kultivierten Mikroorganismen können im Wasser gefunden werden. Wie es bei der Patientin zu der Infektion im Bereich der Nase kam, blieb unklar. Zwei Monate vor der Erstvorstellung hatte sie ein steroidhaltiges Nasenspray verwendet und sich einer Verkleinerung der unteren Nasenmuschel mittels Kauterisierung unterzogen. Möglicherweise hing die Infektion auch mit ihren regelmäßigen Besuchen in einem Thermalbad zusammen.

Prof. Hermann S. FüeßI 